\title{
Microdeletions in FMR2 may be a significant cause of premature ovarian failure
}

\author{
Anna Murray, James Webb, Nick Dennis, Gerard Conway, Newton Morton
}

\begin{abstract}
Genetic causes of premature ovarian failure (POF) include $X$ chromosome deletions and fragile $X$ (FRAXA) premutations. While screening a cohort of women with POF for FRAXA premutations, a more distal trinucleotide repeat, FRAXE, was also tested. We found an unexpected excess of FRAXE alleles with apparently fewer than 11 repeats in the POF group. However, sequence analysis of these alleles showed that the excess was caused by three females who carry cryptic deletions in FMR2, the gene associated with FRAXE. We propose that microdeletions within FMR2 may be a significant cause of premature ovarian failure, being found in $1.5 \%$ of women with the condition, and in only $0.04 \%$ of the general female population. The deletions may affect transcription of either FMR 2 or an adjacent gene.

(f Med Genet 1999;36:767-770)
\end{abstract}

Keywords: FMR2; deletion; premature ovarian failure

FMR2, at the FRAXE locus, is $600 \mathrm{~kb}$ distal to FRAXA in Xq28 and like FRAXA has a trinucleotide repeat within exon $1 .{ }^{1}$ The repeat motif is GCC, which is uninterrupted ${ }^{2}$ and polymorphic in the normal population. Like FRAXA there are both premutations and full mutations of FRAXE. Premutations are unstable, unmethylated, and range from 50-200 repeats, while full mutations are also unstable but are methylated and usually over 200 repeats. Unlike FRAXA, transmission of a full mutation can occur both maternally and paternally and reductions in repeat number are common, particularly during paternal transmission. ${ }^{3}$ The phenotype associated with full mutations of FRAXE is poorly defined: affected subjects have mild to moderate mental impairment, with IQs ranging from 50-100 and often have speech delay. ${ }^{4}$ However, they have no consistent dysmorphic features.

The FMR2 gene covers at least $650 \mathrm{~kb}$ of genomic sequence, with an open reading frame of 3904 bp. $^{67}$ FMR2 has 22 exons and is subject to alternative splicing. ${ }^{8}$ To date, there is no evidence that the repeat itself is transcribed, but transcription has been reported from $23 \mathrm{bp}$ downstream. ${ }^{6}$ The function of FMR2 is unknown but it has sequence homology to $\mathrm{AF}-4$ (MLLT2), a gene on chromosome 4q21 which is thought to encode a transcription activator and is involved in the $\mathrm{t}(4 ; 11)$ translocation found in acute leukaemia.
Deletions of FMR2 have been described and fall into two classes: (1) those that inactivate the gene, two of which led directly to the identification of FMR $2,{ }^{9}$ and (2) deletions discovered by chance while screening for the number of repeats at FRAXE and assumed to be without phenotypic effect. Four deletions in the second class have been reported. ${ }^{10-13}$ These deletions were all within the 288 bp flanking the GCC repeat encompassed by the PCR primers 598 and 603, commonly used for determining FRAXE repeat number. ${ }^{1}$

Premature ovarian failure (POF) is defined as the cessation of menstruation before the age of 40 and occurs in approximately $1 \%$ of women. ${ }^{14}$ The majority of cases are sporadic and idiopathic, but it has recently been shown that approximately $3 \%$ of sporadic and $13 \%$ of familial POF patients carry FRAXA premutations,${ }^{15}$ confirming previous data from fragile $\mathrm{X}$ families suggesting a causative link between FRAXA premutations and POF. In the course of screening for FRAXA in a population of 203 women with POF, we also tested FRAXE and observed an excess of FRAXE alleles with fewer than 11 repeats (minimal alleles). ${ }^{16}$ One female gave a PCR product $6 \mathrm{bp}$ smaller than would be expected from a zero repeat allele, indicating a deletion within the region flanked by the primers, which suggested that the apparent excess of minimal FRAXE alleles in the POF group might also be the result of deletions in sequence flanking the triplet repeat. Therefore all FRAXE alleles with fewer than 11 repeats in women with POF were sequenced and compared to minimal alleles in a control group of females.

\section{Methods}

A total of 209 females with POF were ascertained in one of two ways, either as a diagnostic referral to the laboratory for chromosome testing or from the regional endocrinology clinic at the Middlesex Hospital, London. The control group were 2434 mothers of boys with learning difficulty recruited as part of a fragile X screening survey. DNA was tested for the number of repeats at FRAXA and FRAXE. All minimal FRAXE alleles were sequenced for the POF group, but for the con-

Table 1 Frequency of FRAXE alleles on chromosomes with FRAXA alleles $<51$

\begin{tabular}{lll}
\hline FRAXE allele & $\begin{array}{l}P O F \\
(n=400)\end{array}$ & $\begin{array}{l}\text { Controls } \\
(n=4796)\end{array}$ \\
\hline FMR2 deletion & 3 & 1 \\
$<11$ repeats (no deletion) & 3 & 16 \\
$<11$ repeats (not sequenced) & 0 & 24 \\
$>10$ repeats (not sequenced) & 394 & 4755 \\
\hline
\end{tabular}

4 June 1999

Accepted for publication 16 June 1999 
Table 2 Subjects with minimal FRAXE alleles ascertained because of POF

\begin{tabular}{lllllll}
\hline & ID & FRAXA & $\begin{array}{l}\text { FRAXE } \\
\text { (PCR) }\end{array}$ & $\begin{array}{l}\text { FRAXE } \\
\text { (Seq) }\end{array}$ & Del & $\begin{array}{l}\text { Prox/dist to } \\
\text { rpt }\end{array}$ \\
\hline POF + FXA exp & SW & PRE, 30 & 08,21 & 08 & No & - \\
& & & & & & \\
POF & AM & 30,30 & $-2,15$ & 18 & $59 \mathrm{bp}$ & Dist \\
& AK & 29,36 & 10,17 & 10 & No & Prox \\
& JB & 22,31 & 06,13 & 15 & 27 bp & - \\
& RC & 29,30 & 09,14 & 09 & No & - \\
& MD & 29,29 & 10,18 & 10 & No & - \\
& TS & 30,30 & 09,16 & 09 & No & Prox \\
\hline
\end{tabular}

trols only minimal alleles that were also carried by a male relative were sequenced, because of the technical difficulty of sequencing people who are heterozygous.

PCR AND SEQUENCING

Estimates of the number of GCC repeats at FRAXE were made by PCR amplification with primers 598 and 603, as previously described. ${ }^{17}$ Primer 598 was fluorescently labelled, PCR products were separated on an ABI 377 automated sequencer, and alleles assigned using Genescan and Genotyper software. For sequence analysis, $50 \mathrm{ng}$ of DNA was PCR amplified with primers 598 and U35072 (3 pmol of each), ${ }^{18} 2 \mathrm{mmol} / 1 \mathrm{MgCl}_{2}, 12.5 \%$ DMSO, $0.2 \mathrm{mmol} / 1 \mathrm{dATP}, 0.2 \mathrm{mmol} / 1 \mathrm{dCTP}$, $0.2 \mathrm{mmol} / 1 \mathrm{dTTP}, 0.05 \mathrm{mmol} / 1 \mathrm{dGTP}, 0.15$ mmol/1 7-deaza dGTP (Boehringer), $1 \mathrm{U}$ Amplitaq Gold (PE Applied Biosystems), 0.25 U Pfu polymerase (Stratagene) in a final volume of $15 \mu \mathrm{l}$. After an initial denaturation time of 15 minutes at $95^{\circ} \mathrm{C}, 30$ cycles of $95^{\circ} \mathrm{C}$ for 1.5 minutes, $65^{\circ} \mathrm{C}$ for one minute, and $72^{\circ} \mathrm{C}$ for two minutes were performed. For female heterozygotes the products were separated on a $2 \%$ agarose gel, the smaller band excised, and the DNA eluted into $100 \mu \mathrm{l}$ of $\mathrm{H}_{2} \mathrm{O}$, from which an aliquot of $5 \mu \mathrm{l}$ was used in a second round of amplification with 598 and U35072. PCR products were purified using the Wizard PCR clean-up kit (Promega), eluted in $50 \mu \mathrm{l}$ of $\mathrm{H}_{2} \mathrm{O}$, and concentrated to $10 \mu \mathrm{l}$ in a Speedvac. PCR products were sequenced using the ABI Prism ${ }^{\mathrm{TM}}$ dRhodamine Terminator Cycle sequencing ready reaction kit (PE Applied Biosystems) with $4.8 \mu \mathrm{l}$ of purified PCR product, $4 \mu \mathrm{l}$ of ready reaction mix, 1.75 pmol primer (U35072, 598, or 603), and 10\% DMSO in a final volume of $10 \mu \mathrm{l}$. Following cycle sequencing, products were ethanol precipitated and resuspended in $2 \mu \mathrm{l}$ of formamide loading buffer. Thirty six $\mathrm{cm}$ well-to-read, $4.25 \%$ polyacrylamide gels were used to separate sequencing products on an ABI 377 automated sequencer.

\section{Results}

There is a recognised association between POF and FRAXA premutations and therefore in order to examine the association between FRAXE minimals and POF, the females carrying FRAXA expansions were considered separately. Nine females in the POF group had FRAXA alleles with greater than 50 repeats and one of these had a FRAXE minimal allele. However, sequence analysis of this eight repeat allele did not detect a deletion.

There were 200 POF females with FRAXA repeats less than 51, six of whom appeared to have a FRAXE minimal allele. Three of the six "minimals" were found to have deletions within the FRAXE region flanked by primers 598 and 603 (tables 1 and 2). Subject AM had a $59 \mathrm{bp}$ deletion distal to the GCC repeat (fig 1). The other two deletions were proximal to the FRAXE repeat and, as far as we are aware, are the only examples of deletions in this region (fig 1). JB had a $27 \mathrm{bp}$ deletion and a tract of 15 GCC repeats, consistent with the PCR results.

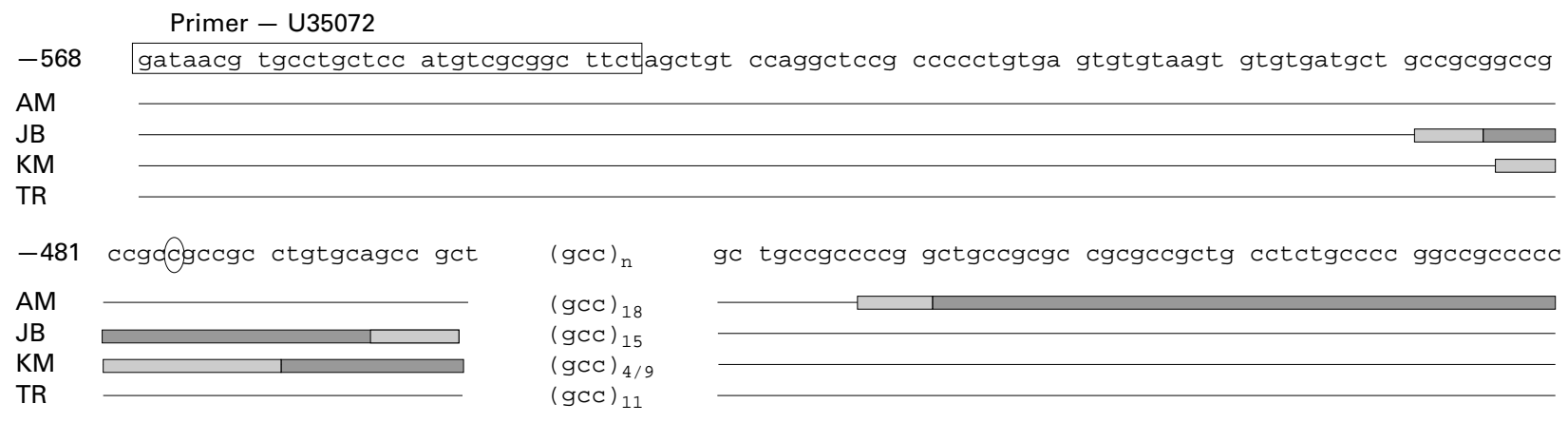

-361 gccgcegctg cegcegccgg cccgcagcca gccaggcggg cggcceagce cgcetgagcc cgcagcggct gccgccgcag cgtcgggtcg

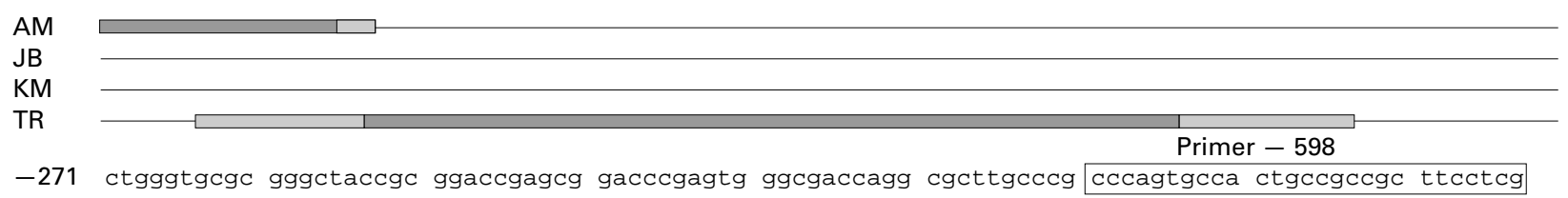

AM

JB

KM

TR

Figure 1 Wild type sequence of part of exon 1 of FMR2 flanked by primers U35072 and 598 (boxed sequence). The positions of deletions in four subjects are shown with filled boxes, the darkly shaded areas are those that are definitely deleted, while the lighter boxes are areas that may be included but it is impossible to determine the exact breakpoints because the sequence is repeated at either side of the deletion. Lines indicate where the sequence is identical to the wild type. The putative transcription start site is circled. 
The deletion in JB includes the putative transcription start site for FMR2. KM had a deletion which overlapped that of JB but adjoined and may have included the repeat itself, leaving between four and nine of the original repeats intact. Because there is a tract of five GCC repeats $12 \mathrm{bp}$ upstream from the polymorphic tract, it is impossible to distinguish the two and so the exact location of the deletion breakpoint cannot be determined. The proximal tract of GCC includes the transcription start site.

Forty one minimal FRAXE alleles were ascertained from the fragile $\mathrm{X}$ screening survey in women not selected for POF. One of these (TR) generated a PCR product $27 \mathrm{bp}$ smaller than predicted for 0 repeats and therefore must include a deletion. Sequencing of this allele showed a $61 \mathrm{bp}$ deletion distal to the GCC repeat (fig 1). TR is 30 years old, menstruates normally, and has one child with learning difficulties, who did not inherit the deletion. Of the 40 remaining subjects with minimal alleles, 16 had male relatives with sufficient DNA for sequencing. None had a deletion. By Fisher's exact test this is significantly different from the frequency of deleted alleles in POF females (table 1, $\mathrm{p}=0.013$ ).

\section{Discussion}

Three of the four deletions detected were found in women ascertained because of POF, suggesting a causal relationship. In a previous publication we reported a significant excess of apparently minimal FRAXE alleles in women with idiopathic POF, but this included those with a FRAXA premutation. ${ }^{16}$ Excluding those with a FRAXA premutation, $1.5 \%$ of chromosomes carried "minimals" compared to $0.85 \%$ in a control population of chromosomes, but in the POF group because three of the six "minimals" were in fact deletions, the incidence of true minimal alleles in females with POF is $0.75 \%$, comparable with the control frequency. Omitting deletions in table 1, Fisher's exact test (one tailed) gives $\mathrm{p}=0.58$, whereas $\mathrm{p}=0.002$ when alleles excluding deletions are pooled. Therefore the apparent excess of minimal FRAXE alleles in women with $\mathrm{POF}^{16}$ can be entirely accounted for by those in whom the minimal is associated with a FRAXA premutation and those who have an FMR2 deletion.

Two of the three POF deletions were near or included the putative transcription start site for FMR2 and are the only reported cases of deletion in this area. It is plausible that deletions in this area could have a dramatic effect on transcription, either by terminating transcription or perhaps by forcing the use of an alternative start site, thus generating aberrant FMR2 transcripts. There is some evidence that a $12 \mathrm{~kb}$ FMR2 transcript which appears to be unique to fetal tissues could be generated by either an alternative $5^{\prime}$ or $3^{\prime} \mathrm{UTR}^{8}$ and it is possible that this fetal isoform could be inappropriately expressed if the conventional transcription start site is lost. It might be expected that if transcription was completely absent from this allele that any effect would be equivalent to having a full mutation at FRAXE, where tran- scription is prevented owing to methylation We only have four females with FRAXE full mutations on the Wessex register who have been involved in our survey of POF in known fragile $\mathrm{X}$ families. Only one of these women had undergone menopause, at the age of 58, and while this does not support the hypothesis that absence of FMR2 causes POF, neither does it discount it. It is likely that $\mathrm{X}$ inactivation ratio plays a large part in any effect, and this cannot be determined in the tissue of interest, namely the ovary. Furthermore, it is possible that unidentified modifying factors may also contribute to the effect of $F M R 2$ inactivation on ovarian function. More females with FRAXE full mutations need to be studied to determine the role of absent FMR2 expression in POF.

The third woman with POF had a deletion distal to the triplet repeat sequence and it is difficult to predict what possible effect such a deletion could have. The deletion overlaps the region known to be deleted in three cases of FRAXA expansion associated with FRAXE deletion, one of whom is from our own laboratory ${ }^{10-13}$ and although there is evidence of an early menopause in female relatives of the full mutation proband in the family we reported, this could easily be caused by the FRAXA premutation which they also carried. Two of the other published cases were also from FRAXA families and no information was given regarding age of menopause in these families. In order to determine the effect of these deletions on FMR2, we aim to collect fresh blood samples and perform expression studies.

An alternative possibility is that these deletions are interfering with an adjacent gene. The FRAXE repeat is in the 5'-GCC-3' orientation with respect to transcription, rather than 5'-CGG-3' orientation of FMR1, which raises the possibility that the FRAXE CpG island acts as a promoter for a second gene transcribed from the opposite strand. ${ }^{6}$ However, to date, no such gene has been identified.

Deletion near the triplet repeat at FRAXE appears to be a relatively common event and we propose the mechanism for this is DNA loop formation owing to the highly repetitive nature of the sequence. ${ }^{19}$ Deletions at FRAXE have been found in $1.5 \%$ of females with POF, independent of expansion at FRAXA, suggesting this is a significant cause of idiopathic POF. While POF is only associated with the premutation class of FRAXA expansion mutations and not the full mutation where gene expression is switched off, ${ }^{20}$ the association with FRAXE appears to be the result of a different mechanism. FMR2 deletions could cause POF either by affecting transcription of FMR2 or transcription of a nearby gene.

We are extremely grateful to Professor Patricia Jacobs for advice and discussion. This work was funded by the Wellcome Trust.

1 Knight SJL, Flannery AV, Hirst MC, et al. Trinucleotide repeat amplification and hypermethylation of a CpG island in FRAXE mental retardation. Cell 1993;74:127-34.

2 Zhong N, Ju W, Curley D, et al. A survey of FRAXE allele Zizes in three populations. Am $\mathcal{F}$ Med Genet 1996;64:415-
sition 19. 
3 Hamel BCJ, Smits APT, Degraaff E, et al. Segregation of FRAXE in a large family: clinical, psychometric, cytogenetic, and molecular data. Am f Hum Genet 1994:55: 923-31.

4 Mulley JC, Yu S, Loesch DZ, et al. FRAXE and mental retardation. F Med Genet 1995;32:162-9.

5 Barnicoat AJ, Wang Q, Turk J, et al. Clinical, cytogenetic and molecular analysis of three families with FRAXE. $\mathcal{F}$ Med Genet 1997;34:13-18

6 Gecz J, Gedeon AK, Sutherland GR, Mulley JC. Identification of the gene FMR2, associated with FRAXE mental retardation. Nat Genet 1996;13:105-9.

$7 \mathrm{Gu} \mathrm{Y}$, Shen Y, Gibbs RA, Nelson DL. Identification of FMR2, a novel gene associated with the FRAXE CCG repeat and CpG island. Nat Genet 1996;13:109-13.

8 Gecz J, Bielby S, Sutherland GR, Mulley JC. Gene structure and subcellular localization of FMR2, a member of a new family of putative transcription activators. Genomics 1997; 44:201-14.

9 Gedeon AK, Keinanen M, Ades LC, et al. Overlapping submicroscopic deletions in Xq28 in two unrelated boys with microscopic deletions in Xq28 in two unrelated boys with developmental disorders: identification of

10 Macpherson J, Murray A, Jacobs PA. FRAXE microdeletions in two interesting families. 7th International Workshop on Fragile X and X-linked Mental Retardation 1995:abstract 65.

11 Zhong N, Yang W, Houck GE, et al. Identification of FRAXE mutations: a FRAXE microdeletion associated with a complex mosaic FRAXA mutation. 7th International Workshop on Fragile $X$ and $X$-linked Mental Retardation 1995:abstract 62 .
12 Holden JJA, JulienInalsingh $\mathrm{C}$, Chalifoux $\mathrm{M}$, et al. Trinucleotide repeat expansion in the FRAXE locus is not common among institutionalized individuals with nonspecific developmental disabilities. Am $\mathcal{F}$ Med Genet 1996;64:420-4

13 Brown TC, Tarleton JC, Go RCP, Longshore JW, Descartes $M$. Instability of the FMR2 trinucleotide repeat region associated with expanded FMR1 alleles. Am $\mathcal{F}$ Med Genet 1997;73:447-55

14 Coulam CB, Adamson SC, Annegers JF. Incidence of premature ovarian failure. Obstet Gynecol 1986;67:604-6.

15 Conway GS, Payne NN, Webb J, Murray A, Jacobs PA. Fragile $\mathrm{X}$ premutation screening in women with premature ovarian failure. Hum Reprod 1998;13:1184-8.

16 Murray A, Webb J, Grimley S, Conway G, Jacobs P. Studies of FRAXA and FRAXE in women with premature ovarian failure. F Med Genet 1998;35:637-40.

17 Murray A, Youings S, Dennis N, et al. Population screening at the FRAXA and FRAXE loci: molecular analyses of boys with learning difficulties and their mothers. Hum Mol Genet 1996;5:727-35.

18 Richards RI, Crawford J, Narahara K, et al. Dynamic mutation loci: allele distributions in different populations. Ann

19 Thacker J, Chalk J, Ganesh A, North P. A mechanism for deletion formation in DNA by human cell extracts: the involvement of short sequence repeats. Nucleic Acids Res 1992;20:6183-8.

20 Allingham-Hawkins DJ, Babul-Hirji R, Chitayat D, et al. Fragile $\mathrm{X}$ premutation is a significant risk factor for premature ovarian failure. (The international collaborative POF in Fragile X study.) Am f Med Genet 1999;83:322-5. 